\title{
IoT based Temperature and Humidity Controlling using Arduino and Raspberry Pi
}

\author{
Lalbihari Barik \\ Department of Information Systems, Faculty of Computing and Information Technology in Rabigh \\ King Abdulaziz University, Kingdom of Saudi Arabia
}

\begin{abstract}
Internet of Things (IoT) plays a pivotal part in our mundane daily life by controlling electronic devices using networks. The controlling is done by minutely observing the important parameters which generate vital pieces of information concerning the functioning of these electronic devices. Simultaneously, this information will transmit these vital statistics from the transmitting device as well as save the same on the cloud to access by the applications and supplementary procedures to use them. This scrutiny associates the outcomes of the environmental observances like the humidity and temperature measurements using sensors. The gathered information could be profitably used to produce actions like distantly dominant cooling, heating devices, or long term statistics, which will be useful to control the same. The detected data are uploaded to the cloud storage through network and associate using android application. The system employs Arduino UNO with Raspberry Pi, HTU 211D sensor device, and an ESP8266 Wi-Fi module. The experimental results show the live temperature and humidity of the surroundings and the soil moisture of any plant using Arduino UNO with Raspberry Pi. Raspberry $\mathrm{Pi}$ is mainly used here for checking the temperature and humidity through the HTU 211D sensor element. The sensors are used for measuring the temperatures from the surroundings, storing displayed information with different devices. Here, the ESP8266 Wi-Fi module has been used for data storing purpose.
\end{abstract}

Keywords-IoT; Raspberry Pi; Arduino UNO; data transmission; sensors

\section{INTRODUCTION}

IoT is used for connecting the electronic devices with the internet. The devices may vary from the temperature measuring equipment and vehicles SOS system to other electronic devices such as sensors, software's, and network connectivity facilities, which sanction collecting and exchanging data. The twentyfirst century has witnessed a massive paradigm shift to and focusing on global attention onto IoT as a burgeoning discipline with multiple possibilities and diverse opportunities for growth and development [1]. Internet connection facilitates the smooth functioning of the devices that have become indispensable parts of our day-to-day lives and existence. The Internet offers the provision to link and network different kinds of devices like sensors and fitness devices. In the changed scenario post the September 11, 2001 attack on the United States where surveillance has gained paramount importance in proposed model security and survival, the internet facilitates wholesome and perfect monitoring systems using closedcircuit cameras [2].
All these devices that enable them to upload input as well as output to the Internet using cloud provisioning. The information thus garnered is accessible for monitoring and analysis anywhere in the globe via the internet [3]. In order to cut down on human effort and involvement, of late people increasingly depend on embedded systems to control and monitor the factors affecting the ecosystem. Temperature and humidity are vital in observing and understanding nature. IoT comes into the picture here by significantly enhancing the efficiency of the mechanism and systematically cutting down on human involvement, and thereby overall expenditure [4].

Practically, every part of exercise contains controlled schedules of temperature as well as humidity. However, the exact value of temperature with its significant feature in any field is essential in monitoring [5]. Constant perception in temperature is utilized in various industries like the pharmaceutical industry as the driving force behind these monitoring systems, computerized and straightforward temperature sensors can use [6]. Resistors, semiconductors, thermistors estimate temperatures values. These components are present inside the sensor to retrieve the temperature in consonance with the circumstances. The primary goal of our system is to supervise the live temperature and humidity within a low cost [7].

Raspberry $\mathrm{Pi}$ is the observational system or controller which is used for the cloud saving. Python is the programming language which is utilized in Raspberry Pi. HTU 211D sensors is a temperature sensor which is used here for the sensing purpose [8]. This comprises of temperature ascertaining capacity and favorable fundamental position of utilizing HTU 211D sensors, which boasts of less weight and ease of use. The sensor is associated with Raspberry Pi utilizing connecting wires. Temperature sensor HTU 211D sensors is utilizing is perused put away, and shown in the Raspberry Pi unit [9].

IoT based devices in homes and industries are used for controlling all the electrical or electronic devices which are present. Additionally, the saved information of the IoT devices can be controlled from anywhere [10]. The sensor analyzes the graphical representation of the observed data in every userdefined format wherever in the world. In this work, IoT based Arduino with Raspberry Pi microcontroller is used. Humidity and temperature monitoring using Arduino is an exciting and secure process. Furthermore, this flexible system obtains more values in calculating the actuator from the data saved on the internet [11]. For connecting the Arduino board with Raspberry $\mathrm{Pi}$, USB line serial interface is essential to connect with any application [12]. 


\section{LITERATURE REVIEW}

Arduino controller system is used for measuring the temperature and wetness of the devices, pressure, and height measurement. The setup contains the height measuring device and a measuring or controlling instrument. In this work, they proposed an Arduino UNO with Raspberry Pi data processing unit [13]. Along with this setup, a Cube satellite is included here to supply the data of weather condition when no network coverage is available. This method has advantages like ease of construction, portable device; price is economical, low power, and a reliable system.

However, there are some disadvantages like not used in long-distance while powerful transceiver sections are not present, and the gas balloon is also hauling, and parts could be broken in the rain or during practice. Alternative energy panel method did a significant role in measuring the aforementioned parameters [14]. The apparent statistical data are first collected and then sent by the use of a GSM module through the receiver. A server is used here for connection and collection of information.

Weather surveillance development system can be used in gathering real-time information as well as for transmission [15]. They have achieved by introducing a VAISALA WXT520 weather transmitter device to transmit the information from one place to another place [16]. This device senses all the ecological parameters and their ratio. Then the collected real-time information's are transmitted wirelessly over a long distance through GSM [17]. This method provides flexibility because, in this method, one can add or remove the measuring parameters. Santhosh et al. [18] had projected a new model for ecological observation applications.

In this method, they proposed a system for patient monitoring and transmitting their measured data to the doctors. The medical base station and variety of distributed wireless device nodes are employed in this work for transmitting and receiving purpose [19]. Here the Base station is developed by Raspberry Pi device node along with the Zigbee [20]. The device is accessed by the use of nodes with internet Wi-Fi for gathering the information from the transmitting place. The web application which is developed is Apache protocol internet server [21]. This method has the following advantages like affordable, compacted, easy to modify, and simple to keep up and have the drawback of group action sensing modalities to receiver nodes [22].
Additionally, internet interface based systems are developed that utilizes a wireless device network (WDN) for agricultural area monitoring [23]. WDN consists of a frequency transmitter and a receiver. AVR-ZigBee, Bluetooth-module, temperature, humidity, soil wet sensors, and LCDs are used in this research [24]. Smart PZT sensors were used as an actuator and receiver, coupled with two XBee's and two Ardiuno as signal generator and signal receiver in damage identification [25]. This method is reliable and economical for agricultural unit's observation system.

\section{ARChitecture OF THE SyStEM}

This part concludes that the combination of Arduino UNO with Raspberry Pi is a perfect method for electronic device monitoring, data collection, and data saving. This paper helps to calculate the humidity and temperature values of the particular surroundings using the DHT-11 Temperature Sensor, and the results are graphically analyzed by one ThingSpeak platform software and an ESP8266 Wi-Fi module [7]. Fig. 1 shows the overall block diagram setup of the proposed system.

In this system, the Arduino mega 2560 Raspberry Pi microcontroller is used for controlling the temperature, water level, and the humidity levels. The Arduino mega 2560 Raspberry Pi microcontroller is the heart of this system also the power supply used here is a solar panel instead of the regular electric supply. Along with this controlling process, the system is capable of switching on and off the DC motor based on the soil water content level as well as the rainy season. Moreover, the system is also portable on the weather forecast.

In this work, the calculation of the humidity and temperature value of the particular surface area is being done using the HTU-211D sensor. The sensor is preferably used for sensing the humidity and temperature of any area. Then the sensors sensed data are controlled and collected by the Arduino UNO with Raspberry Pi microcontroller: Power Supply from solar Panel is served for the microcontroller.

The system is beneficial for farmers to work in the nonpower sector to save electricity. Moreover, the results are graphically analyzed by using the one ThingSpeak platform through the ESP8266 Wi-Fi module. Finally, collected data from the HTU 211D sensor, saved the same data, and analyzed the data by using the cloud data module [8].

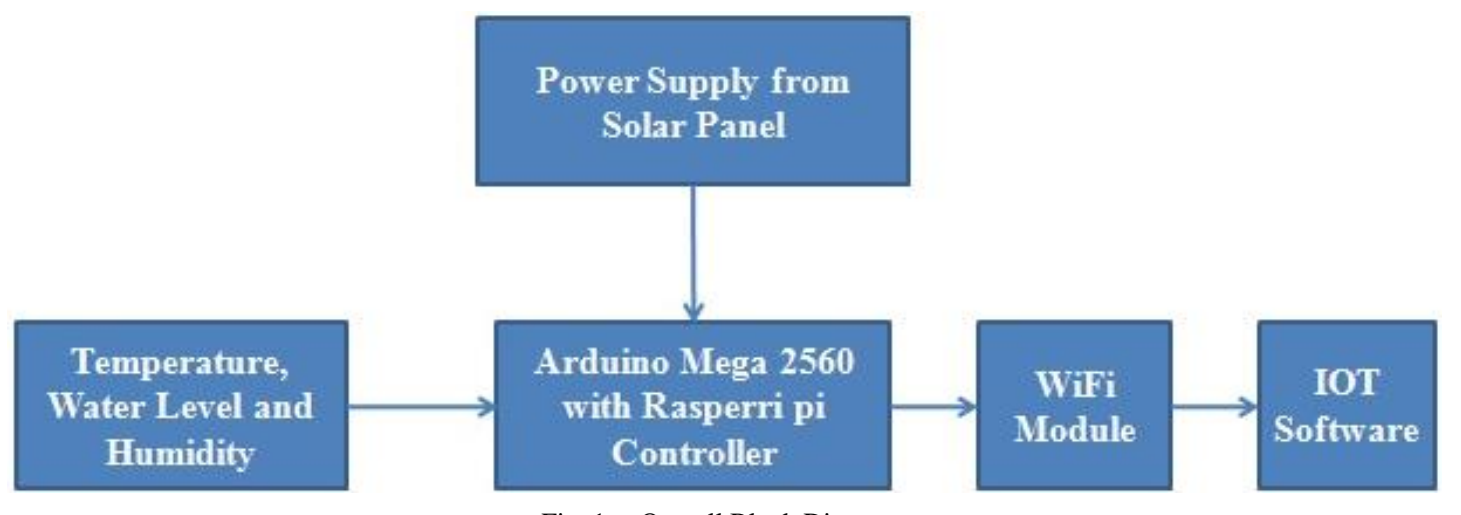

Fig. 1. Overall Block Diagram. 
Fig. 2 shows the solar panel power supply supplied to the whole system. During periods of rain, the battery saved data is supplied. So, this will be beneficial for the farmers in monitoring the agriculture area. Fig. 3 shows the circuit diagram for measuring the humidity and temperature of an area. It shows the solar power supply of the system with an Arduino MCU with Raspberry Pi microcontroller, HTU 211D sensor, and an ESP8266 Wi-Fi module.

Temperature detector which is used here is a 4-pin low price extremely reliable detector named HTU 211D SENSORS. The first pin is connected with a Vcc node point. Here, the utilized power supply is a solar panel. The second pin is an information pin which will collect all the information from outside and provides information to the microcontroller. The sensor pin configuration of HTU 211D sensor detectors is represented in Fig. 3.

The temperature detector is very much useful for getting digital signal output. The HTU 211D SENSOR detector includes a resistive wetness component and is connected to an extraordinarily high-performing-8-bit-microcontroller. This sensor provides the best worth output, fast response, low cost, and is interference-proof. Their temperatures vary from $00 \mathrm{C}$ $550 \mathrm{C}$, and the wetness value is among $20-90 \%$.

To transfer the readings of the device from HTU 211D sensor to open the supply cloud ThingSpeak software, Arduino UNO with Raspberry Pi interfaces at the output with a LAN module named ESP-8266. In this module, ESP-8266 LAN semiconductor device is connected with a full TCP/IP protocol stack. A voltage of $3.3 \mathrm{~V}$ is ideal, which is then connected by Arduino UNO with Raspberry Pi on PC. The calculation is performed using the AT command and wants the desired sequence, to be used as a saver. The module will work on each saver and server. It gets associated when connected to LAN through the module so that it can transmit over the web.

During the testing of the ESP-8266 module, the module is connected with the Arduino UNO Raspberry Pi. Then the programmed Arduino UNO Raspberry Pi set up is connected with the ThingSpeak platform through the ESP8266 LAN module. ESP8266 LAN module acts as a protocol shopper, and it will send the knowledge to ThingSpeak server. ThingSpeak is the best IoT platform used for data collection and storage purposes. Another unique feature of ThingSpeak is the data analysis and comparison module. Comparison between two different days can be accomplished using ThingSpeak platform.

The HTU 211D sensors are used to senses the humidity and temperature, and transfer the collected data through the 5th pin of Arduino MCU connected Raspberry Pi, as shown in Fig. 4. This set up can also control the DC fan, motor, and water levels for supporting farmers. Then the measured values of humidity and temperature values from the Arduino MCU are uploaded to the Cloud.

Fig. 4 is the overall hardware setup of the proposed system. This arrangement the Arduino mega 2560 Raspberry Pi microcontroller is worn to design for calculating the temperature, water level, and the humidity levels of the primary agricultural areas also help the farmers. The Arduino mega 2560 Raspberry Pi microcontroller is the sole of this arrangement, as well as the used power supply in this work, is the solar panel as a replacement for the regular home power supply. Because the solar panel installation only required some amount; after the installation, there is no money spending required. Next to the controlling process of such arrangement, in addition to that, it can switch on and off the DC motor support on the soil water content level as well as the weather season. Furthermore, the system is convenient for the weather forecast.

Then the collected data are transferred to the farmers live through the GSM to their cell phones. Based on the water level measuring system, the collected data are sending to the farmer's cell phone continuously. They can switch on or off their motor based on the collected data from the water level measuring system. This is beneficial for the farmers to control the motors as well as can watch their plants from their house. Moreover, this helps the plants from the overwatering. The system is beneficial for water scarcity problems. The values are uploaded within the stipulated time period through the ESP8266 Wi-Fi system. Then, from the Cloud, the humidity and temperature standards are measured using one ThingSpeak platform from anywhere.

Here, the used open data platform source is ThingSpeak software, which is free. Two-parameter tabs as humidity and temperature are selected in Fig. 5. After the new channel log in two API keys are generated. The original String API Key is "NTIM1RXET6YVUVWF". Then replace the above line with the given program API key. Next, substitute the Host Name and Password with Wi-Fi name and Wi-Fi password. The original String-Hostname is "Jonah" and the password is "2569696".

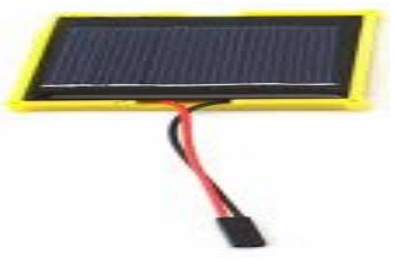

Fig. 2. Solar Panel.

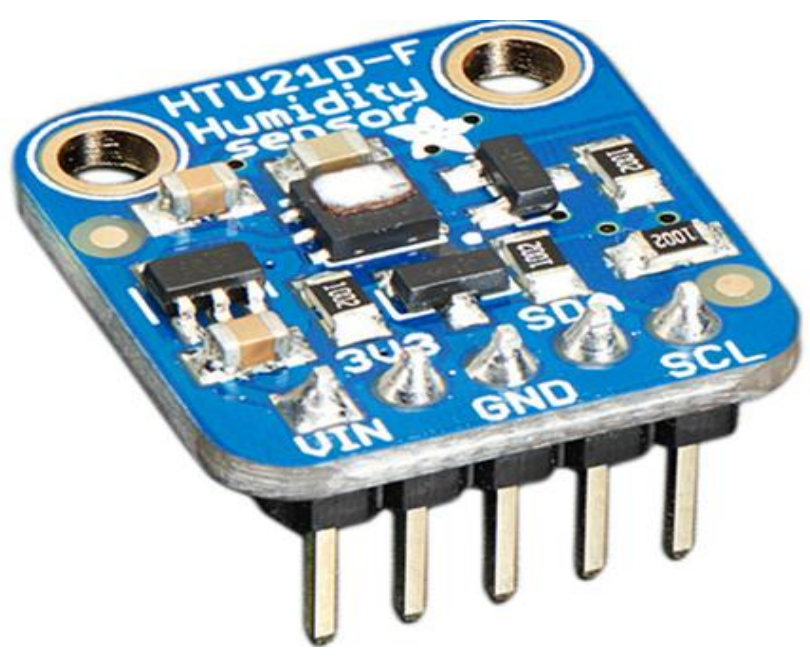

Fig. 3. Adafruit HTU 211D Sensors. 


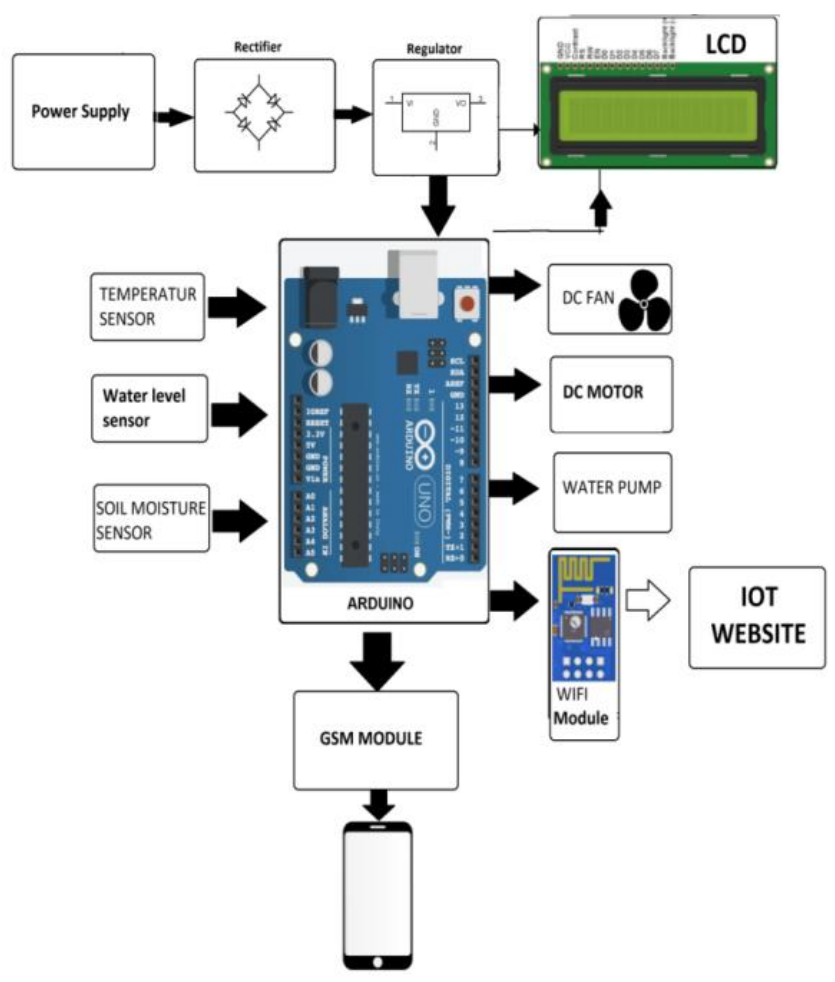

Fig. 4. Circuits and Boards.

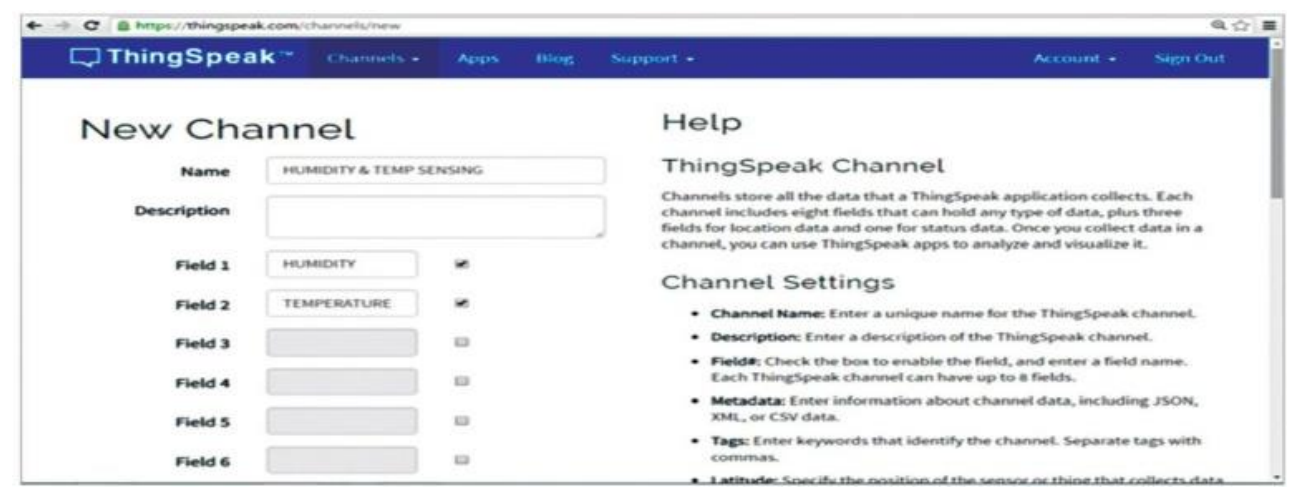

Fig. 5. Cloud, Humidity and Temperature Measurement.

Fig. 6 shows the overall setup with all sensors and cloud. The figure clearly shows the cloud, humidity, and temperature measurement systems. The program should be verified with the Wi-Fi setup. To import the DHT library in Arduino Integrated Development Environment (IDE), select the input sketch from the selected input folder. Then click 'import' to retrieve the data from the library. To save cloud in the library, click 'add library'; then select the library that has downloaded. Compile the sketch/program and upload to Arduino MCU through Arduino IDE. For these steps, better internet connectivity is indispensable, and hence, it should ensure beforehand.

The central unit may be a microcontroller (Arduino UNO) and acts as the central processor unit for the complete system. This unit interfaces with the device chip as the input for receiving temperature and humidness readings. For output, it interfaces with the $\mathrm{Wi}-\mathrm{Fi}$ module to send the received information to the cloud over the web. The microcontroller polls the device to retrieve information and sends over the web to ThingSpeak.

To begin with, Raspberry Pi should be ready, and for that, need NOOBS. It is a software-based system manager that simplifies transfer, install, and then acquired wind of Raspberry Pi. Boot the NOOBS system once in the beginning; then get a variety of operating systems (OS) to decide on from the system. NOOBS makes obtaining started with Pi simple and includes a bunch of in OS to decide. The Raspberry Pi itself does not go together with the software system. Raspbian is the "official" software system of the Raspberry Pi. Raspbian has been the quality Raspberry Pi in OS like UNIX.

Since the system includes temperature and humidity watching, one device interface is required and no native storage of information. Designate Arduino UNO with Raspberry Pi microcontroller that serves the purpose well because of its simplicity, lustiness, and low value. Fig. 6 shows an image of 
Arduino UNO with Raspberry Pi microcontroller utilized in the proposed system. This microcontroller board is predicated on the ATmega328P. The controller has a USB port, 14 digital input/output pins, 6 analog input pins, 16 megacycle quartz with a power jack, and a button. It is battery-powered with a battery. It is programmable with the Arduino IDE via a sort B USB cable.

The all humidity and temperature values will be uploaded on the ThingSpeak platform. After that, one can see its graphical representation of both humidity and temperature values in a separate view window, as shown in Fig. 7. If one wishes to change the channel or field name, one can change it from the channel settings. Finally, the collected data are transferred to the farmers time to time with the GSM to their cell phones. This is beneficial for the farmers to control the motors as well as can watch their plants from their house. The proposed hardware prototype is shown in Fig. 17.

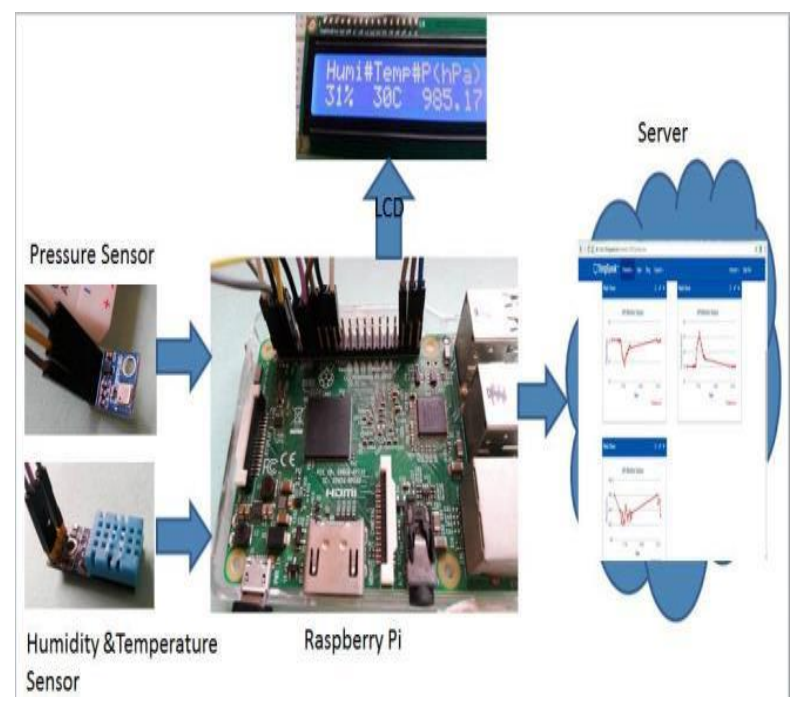

Fig. 6. Overall Set up with All Sensors and Cloud.

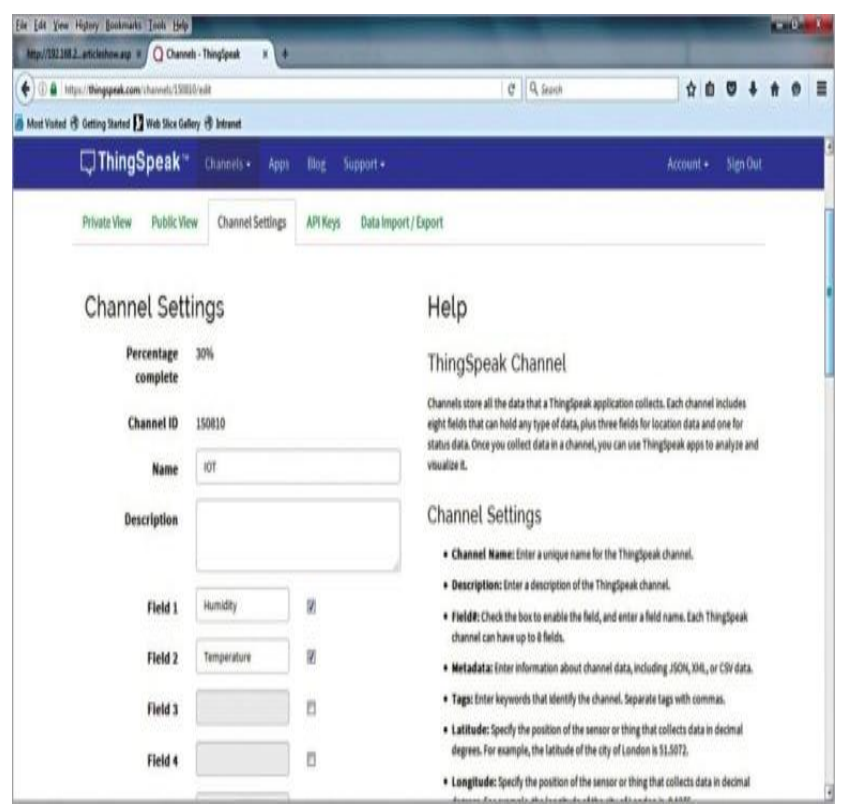

Fig. 7. Channel Settings.

\section{RESUlTS AND DISCUSSION}

IoT based temperature and humidity measurement system provides an economical and safe system. This is very useful for the detection of agricultural-related parameters. The results of the temperature and humidness will see on the Raspbian OS terminal. The central hardware element of the proposed system is the microcontroller that interfaces with alternative elements of the system. Since the system includes temperature and humidity controlling that one device interface is required and no primary storage of information. This designated an Arduino UNO with Raspberry Pi microcontroller.

In this regards, the Arduino mega 2560 Raspberry Pi microcontroller's controlling the temperature, water level, and the humidity levels measurement plots are plotted. The Arduino mega 2560 Raspberry Pi microcontroller used the solar panel instead of the proposed electric supply. The comparisons between the supply usage and their advantages are studied. Moreover, the graphs of the controlling process system, switch on and off the DC motor based on the soil water content level and the weathers forecasting are plotted. Water supply content levels, as well as the rainy season are drawn in the ThingSpeak software.

Fig. 8 shows the water level checking setup. In this setup, the sensor first senses the water level. Then data is then transferred to the farmers live through the GSM to their cell phones. This is beneficial for the farmers to control the motors as well as can watch their plants from their houses.

Fig. 9 shows the comparison between the solar panel powers to standard power. In this work, instead of the standard power supply, a solar panel supply is used. The ThingSpeak software attains the generated power difference to standard power.

Fig.10 graph shows the humidity results of the proposed system. Humidity is the quantity of water vapor present in the air. The water vapor amount is essential to attain the saturation state in proportion with the increase in temperature value. As the temperature of a parcel of air is low, it will eventually reach the saturation point without adding or losing the mass of water. The quantity of water vapor enclosed in the air can vary significantly.

Fig. 11 shows the comparison graph between the temperature and humidity levels every two hours. This is essential for the system. These comparisons are used for the weather forecasting unit of the proposed model. The temperature and humidity levels are proportional to each other.

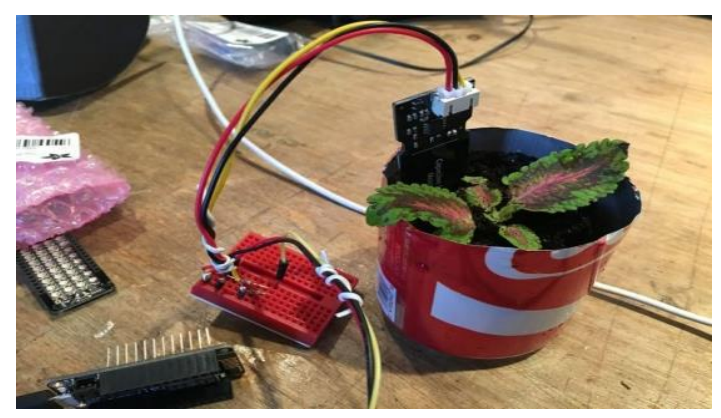

Fig. 8. Water Level Checking Setup. 


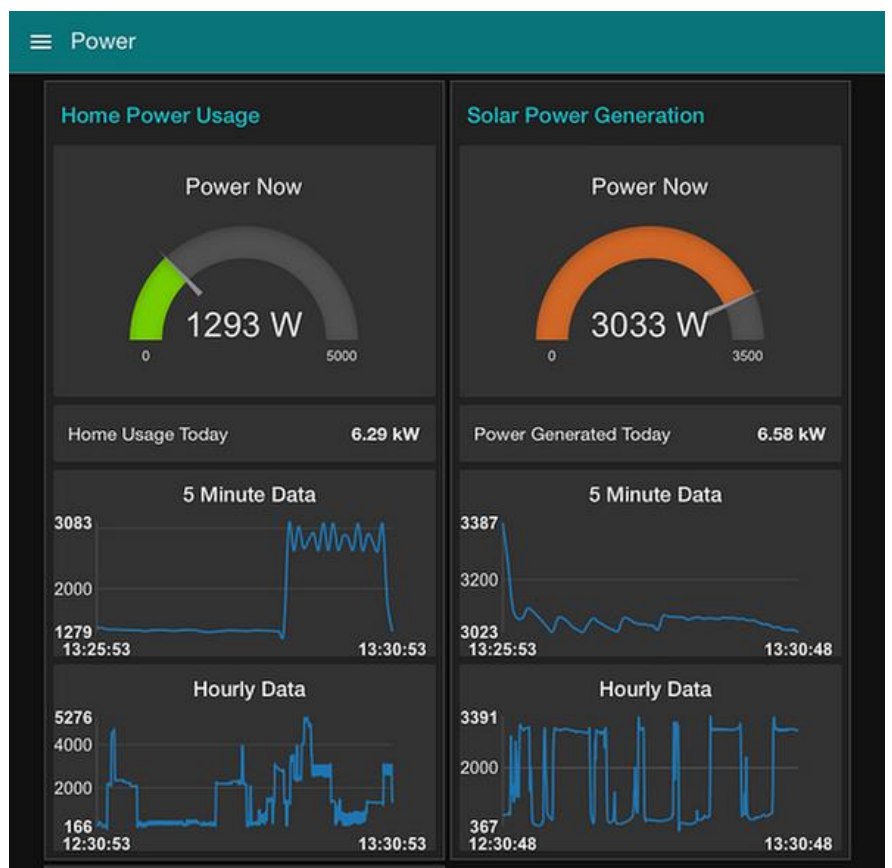

Fig. 9. Comparison between the Solar Panel Powers to Standard Power.

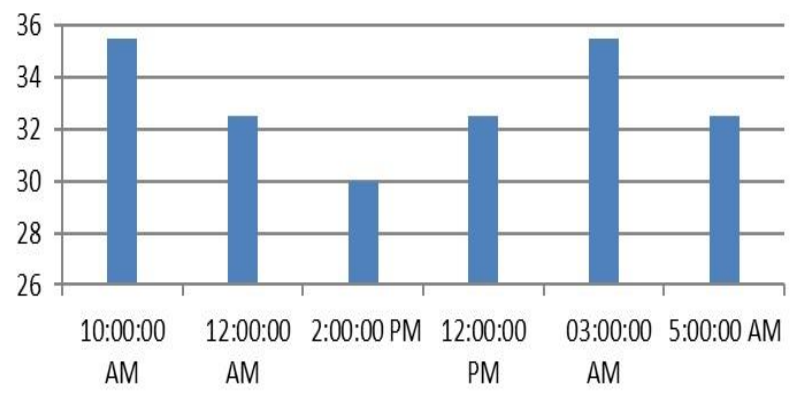

Fig. 10. Graphical view of the Humidity.

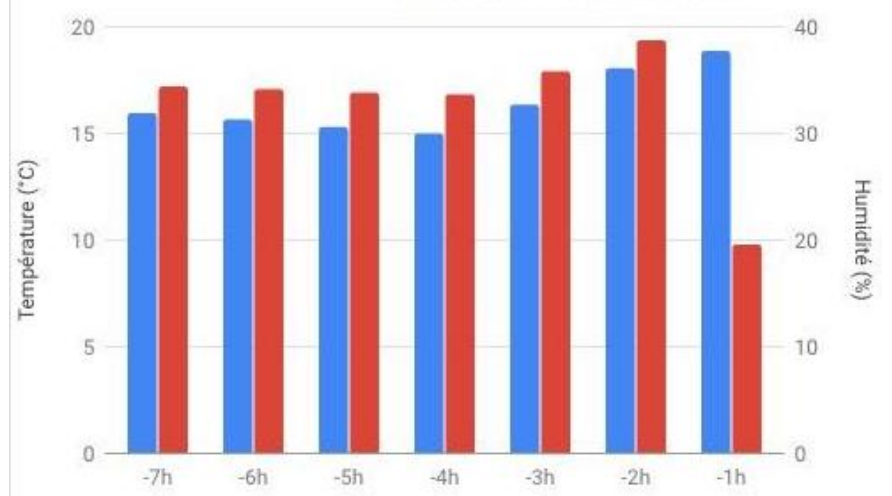

Fig. 11. Comparison between Temperature and Humidity.

Thus, from these results, if the temperature of the surrounding increases, the humidity value of air decreases. Similarly, from the predicted humidity results, if the season is rainy, much water need not be supplied to the plants. This set up can also control the DC fan, motor, and water levels for supporting farmers. Then the measured values of humidity and temperature values from the Arduino MCU are uploaded to the cloud. Then the collected data is communicated uninterruptedly to the farmers live through the GSM to their cell phones. Based on the water level measuring system, the collected data will be sent to the farmer's cell phones continuously. They can switch on or off their motor based on the collected data from the water level measuring system. This is beneficial for the farmers to control the motors.

Fig. 12 shows the Temperature and Humidity in Real-time. It is essential for plants growth level-based systems. The plant's growths are depended upon both the parameters. If the farmers are not conscious in that the plants will die. Besides, it enables them to monitor their plants from within the comforts of their homes. It will also help to ensure that the plants never suffer from over-watering. Again, the system is beneficial when it comes to water scarcity problems. The values are uploaded within the stipulated time period through the ESP-8266 Wi-Fi system. Then, from the cloud, the humidity and temperature standards are measured using one ThingSpeak platform from anywhere.

Fig. 13 shows the Real-time temperature and humidity of the proposed system. This figure shows the flow of the system functionality wherever HTU 211D SENSORS offers live readings of temperature and wetness at the same time to the microcontroller that sends these reading through the Wi-Fi module over the web to the ThingSpeak cloud.

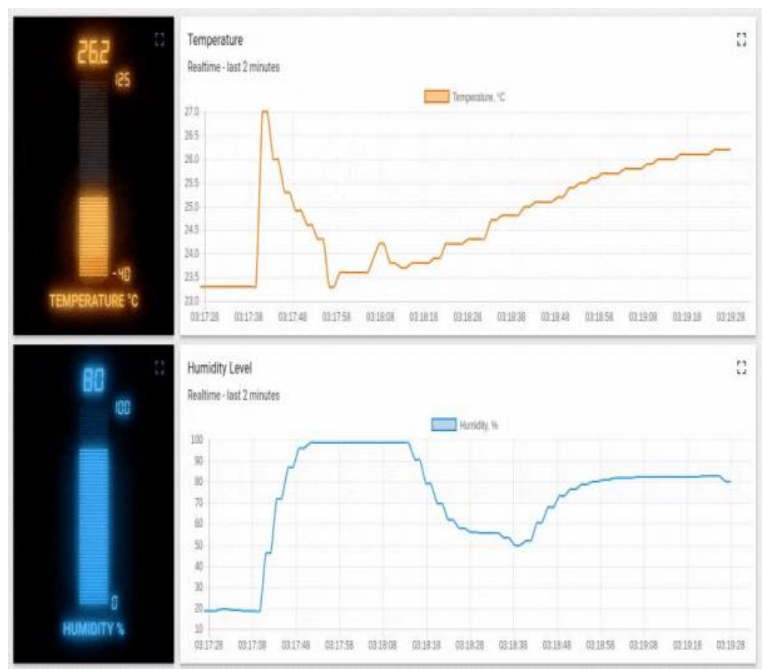

Fig. 12. Temperature and Humidity in Real-Time.

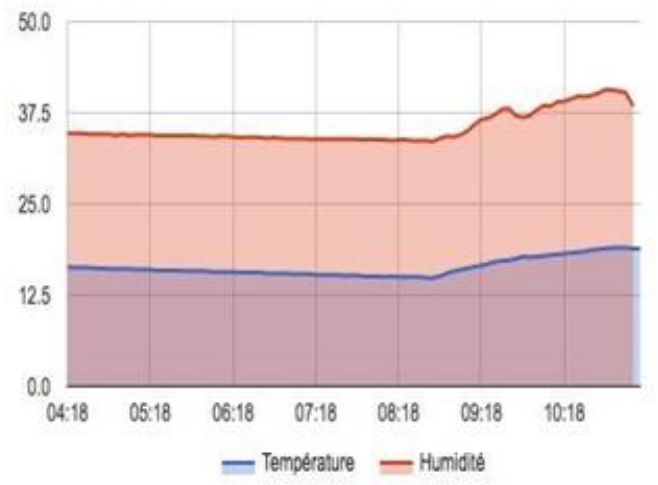

Fig. 13. Real-Time Temperature and Humidity. 
Fig. 14 shows the graphical view of the temperature measurement every two hours. Temperature measurement is a widespread technique in IoT based agricultural monitoring system. Its importance cannot be overstated, whether it is summer or winter, spring or autumn. So, HTU 211D temperature sensor is used in the proposed work environment to sense and monitor the temperature. The temperature of that place is monitored with the help of the internet using IoT.

Fig. 15 shows the measured atmospheric pressure of the proposed model. Temperature monitoring is employed in various applications like temperature, pressure, flow rate, and capacity. In the agricultural area, temperature monitoring is essential because based on the temperature, the plants' growth and photosynthesis happen. So, to monitor the agriculture field, as well as to save the plants from overheat death and to reduce the human effort in this work, the effective utilization of IoT is proposed.

The weather forecasters are essential in the agricultural field. The plant's growths are depended on environmental changes only. Fig. 16 shows the Weather forecast output of the proposed work. It is necessary for the time of agriculture. The farmers can watch all the things from their home. In this work, the humidity, light, wind, and the percentage of rainfall is in the same area. It can monitor and arrange the necessary actions from their own place.

Fig. 17 shows the proposed hardware setup of the humidity and temperature using the Arduino Mega 2560. IoT web based temperature monitoring is a type of temperature recorder that monitors the temperature of the field. Then, it stores the data in a database and displays the live temperature on the website through a web server. The system will continuously monitor the temperature condition of the particular area at anytime and anywhere using the web. The primary reason for promoting this proposed model is user-friendly and makes agriculture smart.

Fig. 18 shows the constant temperature maintenance of the system enhances the process of agriculture at the time of the harvesting process. In this work, the constant humidity and temperature control are necessary.

Fig. 19 shows the single-day temperature graph of the proposed system. It is beneficial for the weather forecasting and the day by day weather monitoring process.

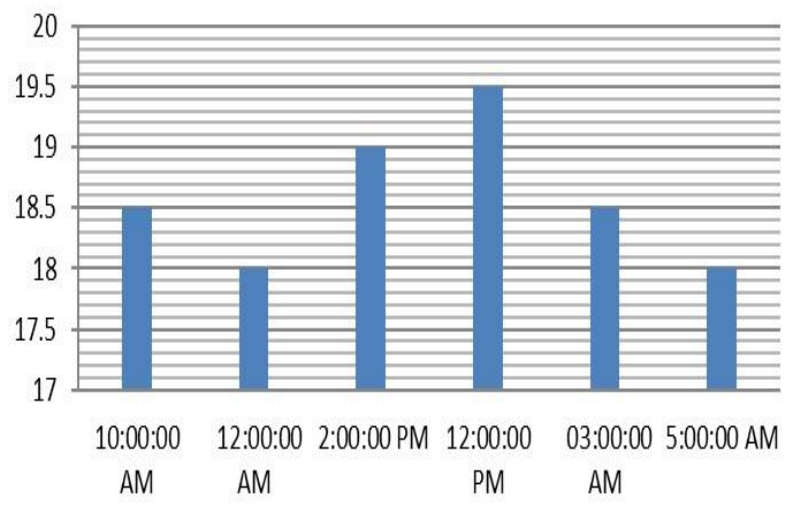

Fig. 14. Graphical view of the Temperature Measurements Every Two Hours.

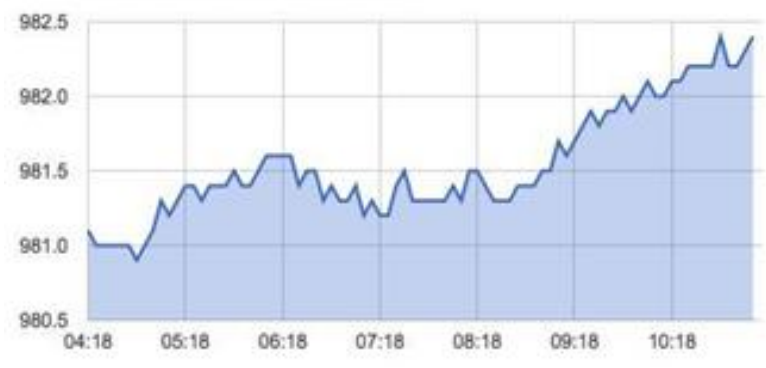

Fig. 15. Measured Atmosphere Pressure.

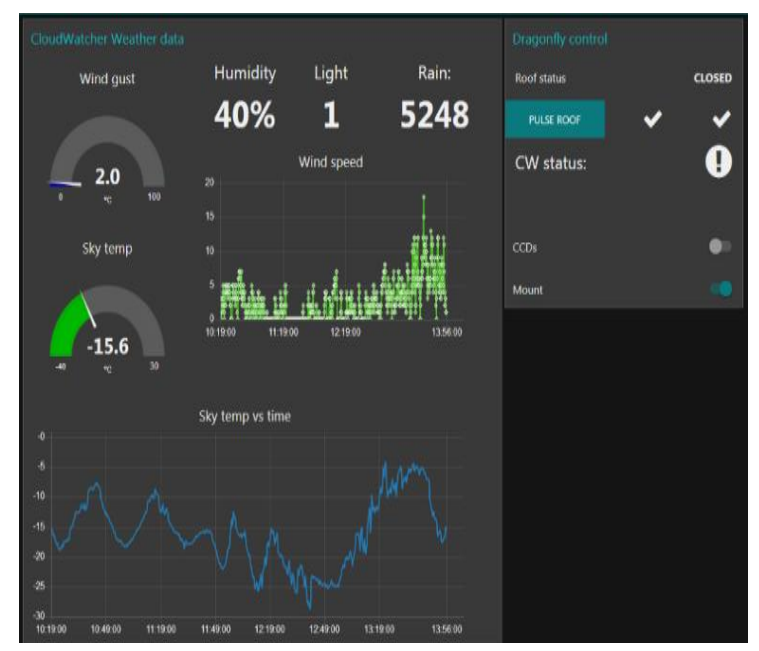

Fig. 16. Weather Forecast Output.

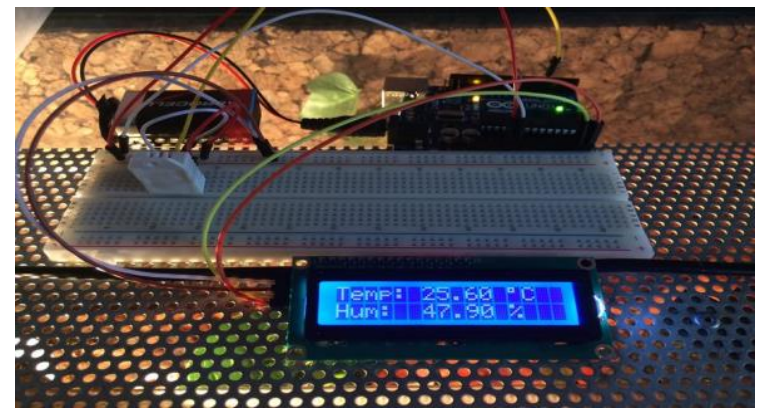

Fig. 17. Proposed Setup of Humidity and Temperature using Arduino Mega 2560.

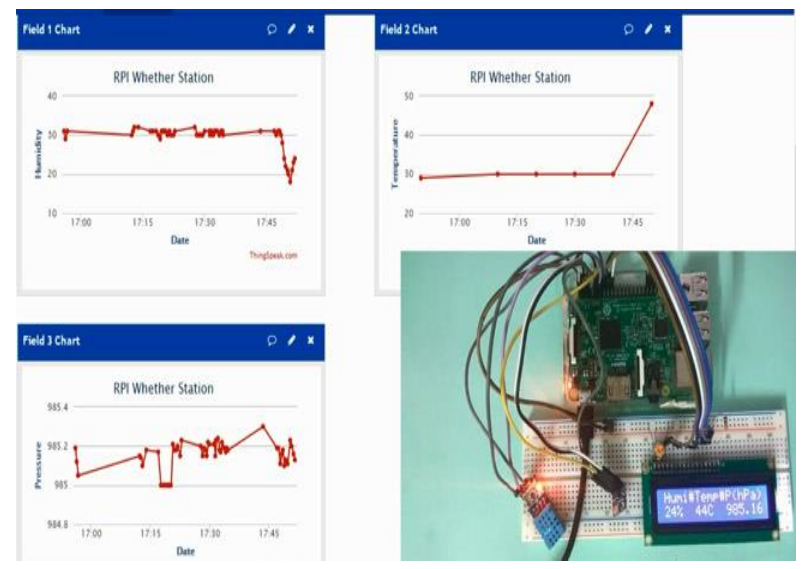

Fig. 18. Constant Temperature Maintenance. 


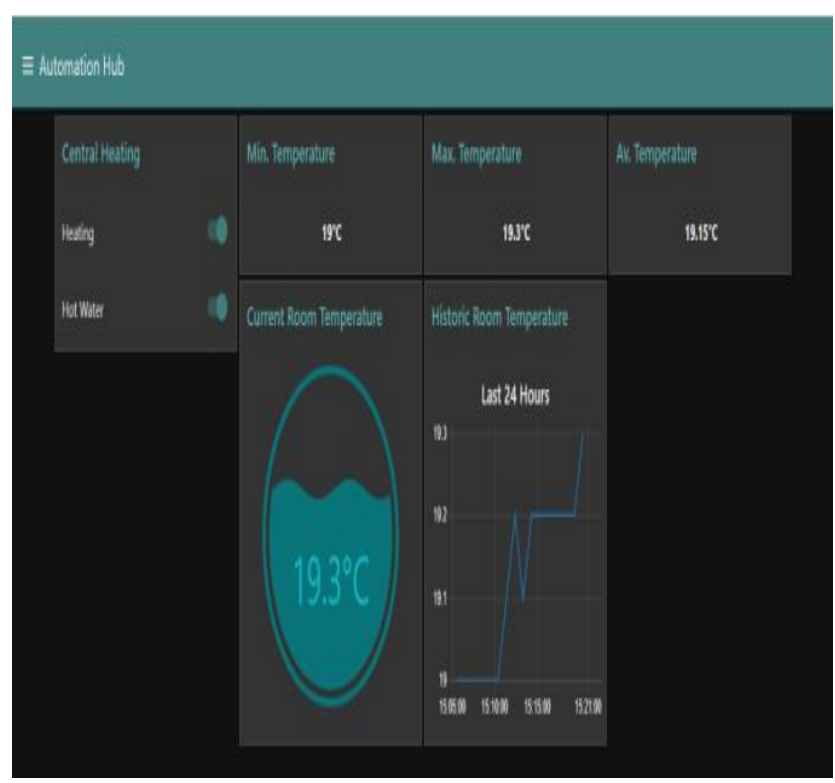

Fig. 19. One Day Temperature Graph.

Table I portrays the comparison between the state of the art methods. In temperature monitoring in the proposed model utilizes sensor monitoring and controlling with Arduino microcontroller. Power usage the Solar panel is used for power saving purpose. In this work, the sensor monitoring and controlling with Arundino controller is used for monitoring the pressure. Finally, the weather conditions and all the above said monitoring plots are done with the ThingSpeak platform.

Fig. 20 shows the DC motor control based on the water level of the soil. The water levels are measured with the water level checking set up shown in Fig. 8. Moreover, from the measured values of the Arduino control, the DC motors are controlled. It is an excellent method for farmers. The proposed work is beneficial for physically challenged peoples who are doing agriculture. It will make a great revolution in agriculture.

Table II shows the comparison between the blockchain models with the IoT system. IoT is centralized with a low latency system. IoT main advantage is the large system adaptation model. That is the reason behind the proposed model.

TABLE. I. COMPaRison Between STATE OF THE ART MEthods

\begin{tabular}{|l|l|l|}
\hline Methods & Existing & Proposed \\
\hline $\begin{array}{l}\text { Temperature } \\
\text { Monitoring }\end{array}$ & $\begin{array}{l}\text { Sensor } \\
\text { monitoring }\end{array}$ & $\begin{array}{l}\text { Sensor monitoring and } \\
\text { controlling with Arundino }\end{array}$ \\
\hline Solar Power usage & Nil & The solar panel is used \\
\hline Controlling systems & Nil & $\begin{array}{l}\text { DC motor monitoring and } \\
\text { controlling by water level }\end{array}$ \\
\hline Humidity Monitoring & $\begin{array}{l}\text { Sensor } \\
\text { monitoring }\end{array}$ & $\begin{array}{l}\text { Sensor monitoring and } \\
\text { controlling with Arundino }\end{array}$ \\
\hline Pressure Monitoring & $\begin{array}{l}\text { Sensor } \\
\text { monitoring }\end{array}$ & $\begin{array}{l}\text { Sensor monitoring and } \\
\text { controlling with Arundino }\end{array}$ \\
\hline Weather forecasting & Nil & With ThingSpeak platform \\
\hline
\end{tabular}

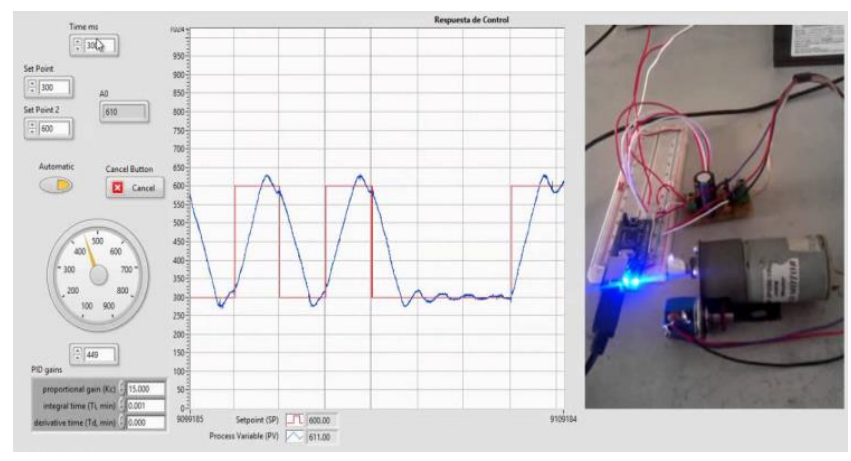

Fig. 20. DC Motor Control by Water Level.

TABLE. II. COMPARISON BETWEen BlockChaIN MODELS With IoT SYSTEM

\begin{tabular}{|l|l|}
\hline Blockchain & IoT \\
\hline Decentralized & Centralized \\
\hline Resource consuming & Resource restricted \\
\hline $\begin{array}{l}\text { Block mining is time- } \\
\text { consuming }\end{array}$ & Demand low latency \\
\hline $\begin{array}{l}\text { Scale poorly with a large } \\
\text { network }\end{array}$ & $\begin{array}{l}\text { IoT considered to contains a large number } \\
\text { of devices }\end{array}$ \\
\hline High bandwidth consumption & $\begin{array}{l}\text { IoT devices have limited bandwidth and } \\
\text { resources }\end{array}$ \\
\hline Has better security & Security is one of the big challenges of IoT \\
\hline
\end{tabular}

\section{Conclusion AND Future SCOPE}

IoT based temperature and humidity detecting device provides an efficient and definitive system for monitoring agricultural parameters. The system also provides a corrective movement or decision-making system. IoT based monitoring of area is a handiest, but it also allows the consumers to research the correct modifications within the surroundings and for taking possible action. It is inexpensive and consumes much less electricity. The Gross Domestic Product (GDP) per capitals in agriculture can be multiplied and helps to add our need parameters.

This set up can also control the DC fan, motor, and water levels for supporting farmers. Then the measured values of humidity and temperature values from the Arduino MCU are uploaded to the cloud. Then the collected data are transferred to the farmers live through the GSM to their cell phones. Based on the water level measuring system, the collected data are sending to the farmer's cell phone continuously. They can switch on or off their motor based on the collected data from the water level measuring system. It is beneficial for the farmers to control the motors as well as can watch their plants from their house. Moreover, also it will help the plants from the overwatering. This system is beneficial for water scarcity problems.

IoT based system can be extended for controlling extraordinary electronic and electric devices from remote locations. Moreover, the system also can be extended for finding the moisture of soil and the farm monitoring for animals growth. 
In the future, the extensive Arduino system can put into practice as agriculture automation system and weather-based fertilizer flower and monitor the value of the plants' growth via the mobile application. IoT based systems are a vital step in sympathetic, relevance growth, accomplishment, and serve as a construction block for a numeral of practical modernization technique controller.

\section{ACKNOWLEDGMENT}

The author thanks King Abdulaziz University for this work.

\section{REFERENCES}

[1] Bhargav Goradiya, and H. N. Pandya, "Real time Monitoring \& Data logging Systemusing ARM architecture of Raspberry pi \& Ardiuno UNO" International Journal of VLSI and Embedded Systems-IJVES. ISSN: 2249 - 6556. Vol 04, PP: 513-517, July 2013.

[2] M. Rahaman Laskar, R. Bhattacharjee, M. Sau Giri, and P. Bhattacharya, "Weather Forecasting using Arduino Based Cube-Sat", Twelfth International Multi-Conference on Information Processing (IMCIP) - 2016.

[3] Vinayak Appasaheb Pujari, M. M. Raste, and A. A. Pujari, "Cost Effective Automatic Weather Station-a Review", International Journal of Electrical and Electronics Engineers (IJEEE)-Vol. No. 8 Issue 01, January-June 2016.

[4] C. H. Chavan, and V. Karande, "Wireless Monitoring of Soil Moisture, Temperature and Humidity using Zigbee in Agriculture", International Journal of Engineering Trends and Technology (IJETT)-Volume 11 Number 10 - May 2014.

[5] Mayur Randhir, R. R. Karhe, "Monitoring Of Environmental Parameters by Using Cloud Computing" International Journal of Computer Science Trends and Technology (IJCST) - Volume 3 Issue 3, PP: 151-155. MayJune 2015.

[6] Nelson Gonzalez, Charles Miers, Fernando Red'igolo, Marcos Simpl'ıcio, Tereza Carvalho, Mats N"aslund and Makan Pourzandi, "A quantitative analysis of current security concerns and solutions for cloud computing" Journal of Cloud Computing: Advances, Systems and Applications 2012, 1:11.

[7] Mahesh D. S, Savitha S, and Dinesh K. Anvekar, "A Cloud Computing Architecture with Wireless Sensor Networks for Agricultural Applications"International Journal of Computer Networks and Communications Security Vol.2, No.1, January 2014, 34-38 Available online at: www.ijencs.org ISSN 2308-9830.

[8] C. H. Chavan, and P. V.Karande, "Wireless Monitoring of Soil Moisture, Temperature \& Humidity Using Zigbee in Agriculture" International Journal of Engineering Trends and Technology (IJETT) Volume 11 Number 10 - May 2014.

[9] Basil Ahammed, Design \& Implementation of Smart House Control Using LabVIEW, International Journal of Soft Computing and Engineering (IJSCE), 1 (6), 2012.

[10] Dingrong Yuan, Shenglong Fang, Yaqiong Liu, The design of smart home monitoring system based on WiFi electronic trash, Journal of Software, 9 (2), 2014, 425-428.
[11] Jiansheng PENG W.L, Qiwen HE, Design of smart home system based on the wireless MCU CC2510, Journal of Hechi University, 10, 2008.

[12] Patricio G, Gomes L, Smart house monitoring and actuating system development using automatic code generation, Industrial Informatics, 7th IEEE International Conference, 256-261, 2009, 23-26. Vinay Sagar K.N, Kusuma S.M, Home Automation using Internet of Things, IRJET, 02,2015 .

[13] Girish Birajdar "Implementation of Embedded Web Server Based on ARM11 and Linux using Raspberry PI" International Journal of Recent Technology and Engineering (IJRTE) ISSN: 2277-3878, Volume-3 Issue-3, July 2014.

[14] Roselle B. Anire et al., "Environmental Wireless Sensor Network using Raspberry $\mathrm{Pi} 3$ for Greenhouse Monitoring System", IEEE 9th International Conference on Humanoid, Nanotechnology, Information Technology, Communication and Control, Environment and Management (HNICEM), 2017.

[15] KonstantinosTzortzakis, et al., "Wireless Self Powered Environmental Monitoring System for Smart Cities based on LoRa", Panhellic Conference on Electronics and Telecommunications (PACET), 2017.

[16] Munsyi et al., "An Implementation of Data Exchange Using Authenticated Attribute-Based Encryption for Environmental Monitoring", 2017 International Electronics Symposium on Knowledge Creation and Intelligent Computing (IES-KCIC).

[17] Somansh Kumar, "Air Quality Monitoring System Based on IoT using Raspberry Pi”, International Conference on Computing, Communication and Automation (ICCCA 2017).

[18] Cho ZinMyint, Lenin Gopal et al., "WSN-based Reconfigurable Water Quality Monitoring System in IoT Environment", 2017 14th International Conference on Electrical Engineering or Electronics, Computer, Telecommunication and Information Technology.

[19] SanketSalvi, Pramod Jain et al., "Cloud Based Data Analysis and Monitoring of Smart Multi-level Irrigation System Using IoT" International Conference on I-SMAC (IoT in Social, Mobile, Analytics and Cloud), 2017.

[20] Alif Akbar Pranata, Jae Min Lee et al., "Towards an IoT-based Water Quality Monitoring System with Brokerless Pub/Sub Architecture" IEEE Transaction on Instrumentation and Measurement 2017.

[21] HakanUcgun, et al., "Arduino Based Weather Forecasting Station", 2nd International Conference on Computer Science and Engineering 2017.

[22] J.Cabra, D.Castro et al., "An IoT approach for Wireless Sensor Networks applied to e-health environmental monitoring", 2017 IEEE International Conference on Internet of Things and IEEE Green Computing and Communications and IEEE Cyber, Physical and Social computing and IEEE Smart Data.

[23] Pablo Velasquez, et al., "A low-cost IoT based Environmental Monitoring System. A citizen approach to pollution awareness", 2017 CHILEAN Conference on Electrical, Electronics Engineering, Information and Communication Technologies (CHILECON).

[24] Nikolas Vidakis et al., "Environmental Monitoring through Embedded System and Sensors", 52nd International conference on Power Engineering Universities, 2017.

[25] Shirazi et. al.. "Damage identification using wireless structural health monitoring system through smart sensor application", International Journal of Advanced and Applied Sciences 4.2. 2017: 38-43. 